\title{
Effect of Exposure to Selective Serotonin Reuptake Inhibitors In Utero on Fetal Growth: Potential Role for the IGF-I and HPA Axes
}

\author{
SHMUEL DAVIDSON, DIANA PROKONOV, MICHAL TALER, RACHEL MAAYAN, DANIELLA HARELL, IRIT GIL-AD, \\ AND ABRAHAM WEIZMAN
}

\begin{abstract}
Department of Neonatology [S.D., D.P.], Helen Schneider Hospital for Women and Biochemistry Laboratory [D.H.], Rabin Medical Center, Petah Tiqwa 49100, Israel; Laboratory of Biological Psychiatry [M.T., R.M., I.G.-A., A.W.], Felsenstein Medical Research Center, Beilinson Campus, Petah Tiqwa 49100, Israel
\end{abstract}

\begin{abstract}
To investigate the possible effect of fetal exposure to selective serotonin reuptake inhibitors (SSRIs) on somatic growth and on hormones of the hypothalamic-pituitary-adrenal (HPA) and insulin-like growth factor (IGF)-I axes, we compared the anthropometric parameters and hormonal profile of 21 SSRI-exposed infants and 20 matched controls. The SSRI group was characterized by lower crown-heel length $(p<0.01)$, smaller head circumference $(p=$ 0.08 ), and higher percentage of infants with birth weight, birth length, and head circumference below the 10th percentile $(p<0.045$, $p=0.08, p<0.04$, respectively), in addition to a significantly lower cord blood level of cortisol $(p<0.03)$ and higher level of thyroidstimulating hormone (TSH) $(p<0.004)$. Infants exposed to citalopram had a lower cord blood IGF-I level than infants exposed to paroxetine $(p<0.001)$ and controls $(p<0.003)$. Placental IGF-I receptor (IGF-IR) expression was significantly higher in the SSRI group than in controls $(p<0.01)$. Urine 5-hydroxyindoleacetic acid (5-HIAA) level was negatively correlated with birth weight $(r=$ $-0.71, p<0.025)$ and with dehydroepiandrosterone (DHEA) level $(r=-0.71, p<0.025)$. The Finnegan score was correlated with dehydroepiandrosterone sulfate (DHEAS) $(r=0.8, p<0.005)$ and cortisol $(r=0.62, p=0.05)$. Fetal exposure to SSRIs causes impaired intrauterine growth accompanied by alterations in the IGF-I and HPA axes. The findings may raise concern regarding maternal use of SSRIs during pregnancy. (Pediatr Res 65: 236-241, 2009)
\end{abstract}

$\mathrm{T}$ The reported prevalence of depression in women of childbearing age and during pregnancy ranges from 10 to $15 \%$ (1-3). Treatment usually consists of selective serotonin reuptake inhibitors (SSRIs), especially citalopram, fluoxetine, paroxetine, sertraline, and fluvoxamine. However, their safety for the fetus has not been fully established. Findings regarding major congenital malformations are conflicting (4-6). Several recent studies suggest that although individual SSRIs may confer an increased risk of some specific birth defects (as expressed by the odds ratios), there is only a slight effect on absolute risk (7-9). Others observed that third-trimester intake of SSRIs accounts for symptoms of poor neonatal adaptation (10-14) and, consequently, higher-than-normal rates of ad-

Received May 9, 2008; accepted October 6, 2008.

Correspondence: Shmuel Davidson, M.D., M.Sc., Department of Neonatology, Helen Schneider Hospital for Women, Rabin Medical Center, Petah Tiqwa 49 100, Israel; email: shmueld@clalit.org.il

The study was supported in part by a grant from the Lydia Eviatar Foundation, Schneider Children's Medical Center of Israel, Petah Tiqwa, Israel. mission to neonatal special care and intensive care units $(10,15)$. According to a 2005 literature review, SSRI exposure is associated with an overall risk ratio of 3.0 (95\% CI, 2.0-4.4) for neonatal behavioral syndrome (12); one study also reported an alarming complication of persistent infantile pulmonary hypertension (16). It remains unclear, however, if these symptoms are a manifestation of abrupt drug withdrawal at delivery or of serotonergic overstimulation during pregnancy. Studies have shown that maternal SSRI intake during pregnancy induced a significant reduction in cord blood levels of serotonin and 5-hydroxyindoleacetic acid (5-HIAA) $(1,17)$. Laine et al. (1) reported that the cord blood 5-HIAA level was inversely and significantly correlated with the clinical serotonergic symptom score and attributed this finding to the increase in central nervous system (CNS) serotonin activity.

The question of whether in utero exposure to SSRIs affects birth weight and/or length and head circumference is also unresolved. Some studies noted decreased values of these parameters $(18-21)$, whereas others did not $(1,2,5)$. Growth attenuation accompanied by impaired growth hormone $(\mathrm{GH})$ secretion was also reported in four children and adolescents treated with SSRIs for various psychiatric disorders (22).

Insulin-like growth factor-I (IGF-I), a GH- dependent hormone, is known to play a major role in fetal growth $(23,24)$, but there is limited information on the response of the fetal IGF-I/GH axis to maternal SSRI intake, or the response of the fetal hypothalamic-pituitary-adrenal (HPA) axis, which is involved in serotonin regulation of cortisol and adrenocorticotropic hormone (ACTH) secretion (25-27). In a sheep model, fetal plasma ACTH and cortisol significantly increased after chronic maternal fluoxetine administration (26), raising concerns of fetal exposure to excess glucocorticoids at critical periods during development. Human epidemiologic observations and animal studies have shown that under suboptimal in utero conditions, individual tissues and organ systems can be programmed, with adverse consequences for their function in later life (28-30). Fetal programming of the HPA axis may be

Abbreviations: DHEA, dehydroepiandrosterone; DHEAS, dehydroepiandrosterone sulfate; 5-HIAA, 5-hydroxyindoleacetic acid; HPA, hypothalamic-pituitary-adrenal; IGF-IR, insulin-like growth factor-I receptor; SSRIs, selective serotonin reuptake inhibitors 
one of the long-term changes that link reduced fetal growth and low birth weight with adult cardiovascular disease, hypertension, impaired glucose tolerance, and insulin resistance (the metabolic syndrome) (30).

The objective of the present study was to assess the short-term outcome (neonatal adaptation, anthropometry, level of stress hormones, and growth factors) of newborns exposed to different SSRIs during fetal life and to examine possible physiologic associations among these variables. Because SSRIs modify the level of hypothalamic 5-HT and other catecholamines that play a role in the regulation of pituitary hormones, we considered it important to evaluate their role on the hormonal profile of exposed neonates.

\section{METHODS}

Patients. The study sample consisted of 41 women who gave birth to singleton infants at Rabin Medical Center from July to December 2005. Twenty-one women took SSRIs during the entire pregnancy, and 20 were healthy and did not take SSRIs or other medications (comparison group). The two groups were matched for gestational age ( $\pm 1 \mathrm{wk})$. Women with diabetes, chronic hypertension, and cardiovascular diseases were excluded from participation in the study.

Procedure. A detailed questionnaire covering anthropometry, medical illnesses, and medications during pregnancy was completed for each participant after delivery. No data were available on the severity of the maternal depression or maternal socioeconomic status. Just before delivery, $10 \mathrm{~mL}$ of cord blood were drawn for measurement of the following hormones: thyroidstimulating hormone (TSH), IGF-I, prolactin, cortisol, and dehydroepiandrosterone (DHEA) and dehydroepiandrosterone sulfate (DHEAS). In addition, immediately after delivery, placental tissue was collected from 12 control and 10 SSRI-exposed women for measurement of placental IGF-I receptor (IGFIR) expression.

A urine sample was obtained from each newborn in the first $12-24 \mathrm{~h}$ of life for measurement of 5-HIAA. The SSRI group was followed after birth according to our standardized protocol for drug-exposed infants: medical staff observation for at least $48 \mathrm{~h}$ with the infant naked in the incubator, and continuous recording of the vital signs and symptoms included in the Finnegan score, an accepted method for monitoring onset, progression and improvement of neonatal abstinence syndrome in passively exposed neonates (31). The score lists 21 symptoms related to CNS, metabolic/vasomotor/ respiratory, and gastrointestinal disturbances commonly seen in exposed neonates. The scores for each symptom are added to yield a total score. A repeated score higher than eight is considered an indication for pharmacotherapy. The control infants were examined once a day by one of the authors (D.P.) until discharge. In all infants, birth weight, crown-heel length, and head circumference were measured and plotted against the department's newly developed growth references (32), according to our routine procedure.

The study protocol was approved by the Ethics Committee (Helsinki) of Rabin Medical Center. Written informed consent was obtained from all participants in the delivery room, before enrollment in the study.

Laboratory determinations. Cord blood (artery) and placental tissue samples were frozen on dry ice and maintained at $-70^{\circ} \mathrm{C}$ until assayed. Neonatal urine samples were maintained at $4^{\circ} \mathrm{C}$ until assayed.

DHEA was determined with the DSL 9000 Active $^{\text {TM }}$ DHEA-coated tube RIA kit (Diagnostic Systems Laboratories, Webster, TX): sensitivity 0.07 $\mathrm{nmol} / \mathrm{L}$; specificity-cross-reactivity with DHEA-S $0.88 \%$, all others negligible; assay variability $10.2 \%$ between runs, $5.6-10.6 \%$ within runs, according to level.

DHEAS was determined with the DSL-3500 Active ${ }^{\text {TM }}$ DHEA-S-coated tube RIA kit (Diagnostic System Laboratories): sensitivity $46 \mathrm{nmol} / \mathrm{L}$; specificity-cross-reactivity with DHEA $41 \%$; assay variability $10 \%$ between runs, $6.3-9.4 \%$ within runs, according to level.

Cortisol was determined with the Cortisol-TKCO1 Coat-A-Count kit (Diagnostic Products Corporation, Los Angeles, CA): sensitivity $5.54 \mathrm{nmol} / \mathrm{L}$; specificity-cross-reactivity: with prednisolone $76 \%$, 11-deoxycortisol $11.4 \%$, prednisone $2.3 \%$, cortisone and corticosterone $1 \%$, all others - $<0.3 \%$; assay variability $4.0-6.4 \%$ between runs, $3-4.8 \%$ within runs, according to level.

TSH was determined with the DSL-5300 Active $^{\text {TM }}$-coated tube immunoradiometric assay kit (Diagnostic Systems Laboratories): sensitivity 0.03 $\mathrm{mcIU} / \mathrm{mL}$; specificity-cross-reactivity with similar hormones, negligible; as- say variability $3.3-9.2 \%$ between runs, $1.7-4.7 \%$ within runs, according to level.

Prolactin was determined with the DSL-4500 Active ${ }^{\mathrm{TM}_{\text {-coated }}}$ tube immunoradiometric assay kit (Diagnostic Systems Laboratories): sensitivity: 0.1 $\mathrm{ng} / \mathrm{mL}$; specificity-cross-reactivity with similar hormones, negligible; assay variability $4.6-11.2 \%$ between runs, $1.7-4.4 \%$ within runs, according to level.

IGF-I was determined with the DSL-2800 Active $^{\mathrm{TM}}$ nonextraction IGF-Icoated tube immunoradiometric assay kit (Diagnostic Systems Laboratories): sensitivity $2.06 \mathrm{ng} / \mathrm{mL}$; specificity-cross-reactivity with similar hormones, negligible; assay variability $4.2-7.4 \%$ between runs, $3.9-7.0 \%$ within runs, according to level.

Western blot for IGF-IR. To measure IGF-IR protein expression, total protein lysates from human placenta were extracted with lysis buffer $(150 \mathrm{mM}$ $\mathrm{NaCl}, 5 \mathrm{mM}$ ethylenediaminetetraacetic acid, $1 \%$ Nonidet P-40, $0.5 \%$ sodium deoxycholate, $1 \mathrm{mM} \mathrm{Na} 2 \mathrm{VO} 4,200 \mathrm{mM}$ HEPES, and $50 \mathrm{mMNaF}$ ). The proteins were cleared by centrifugation at $14,000 \times g$ for $20 \mathrm{~min}$ at $4^{\circ} \mathrm{C}$. Protein concentration was determined with the BCA kit (Pierce Biotechnology, Rockford, IL). For Western blot analysis, $50 \mu \mathrm{g}$ protein from each sample were resolved on $7.5 \%$ sodium dodecyl-sulfate PAGE (SDS-PAGE). Electroblotted proteins were detected using polyclonal anti-IGF-IR antibody (Santa Cruz Biotechnology, Santa Cruz, CA) polyclonal antiactin antibody or monoclonal antiactin antibody (Biomeda, Burlingame, CA). Bound antibodies were visualized using chemiluminescence reaction (Pierce).

High performance liquid chromatography for 5-HIAA. Urine 5-HIAA was assayed in random urine samples and reported in micrograms per milligram creatinine. All analyses were performed on a high performance liquid chromatography system using an LC-4C electrochemical detector (BAS, Tokyo, Japan). Separation was achieved on a Lichrochart column (RP-18, 125-4; Merck, Damstadt, Germany) at $35^{\circ} \mathrm{C}$, with chloracetic acid containing $8 \%$ methanol, $\mathrm{pH} \mathrm{3}$, as the mobile phase.

The day-to-day variation (expressed as CV\%) was $3.8 \%$ at $3.12 \mu \mathrm{g} / \mathrm{mL}$ and $5.7 \%$ at $28.9 \mu \mathrm{g} / \mathrm{mL}$.

Statistical analysis. Student $t$ test and analysis of variance were used to compare continuous variables between the groups, and Fisher exact test or $\chi^{2}$ test, as appropriate, was used to compare categorical values. Univariate correlation coefficients controlled for gestational age (partial correlation) were calculated to express the association between the anthropometric measurements and the level of the hormones. Hormone levels were expressed as mean \pm SEM with $95 \%$ confidence intervals for the mean differences; $p<$ 0.05 was considered statistically significant. Statistics were performed using SPSS 10-0 (SPSS, Chicago, IL).

\section{RESULTS}

The SSRIs were administered throughout the entire pregnancy: eight mothers (38\%) received paroxetine, seven (33\%)

Table 1. Maternal and neonatal characteristics (mean \pm SEM) in the SSRI-exposed and control groups

\begin{tabular}{lccc}
\hline & SSRI & Control & $p$ \\
\hline Number & 21 & 20 & \\
Age (yr) & $30.4(1.0)$ & $29.0(0.96)$ & $\mathrm{NS}$ \\
Weight before (kg) & $62.7(2.8)$ & $64.5(4.1)$ & $\mathrm{NS}$ \\
Weight gain $(\mathrm{kg})$ & $11.9(1.3)$ & $13.2(1.1)$ & $\mathrm{NS}$ \\
Height $(\mathrm{cm})$ & $163.8(1.2)$ & $165.4(1.2)$ & $\mathrm{NS}$ \\
Body mass index & $23.4(1.1)$ & $23.5(1.4)$ & $\mathrm{NS}$ \\
Gestational age (wks) & & & \\
$\quad$ Mean & $38.6(0.29)$ & $38.9(0.32)$ & $\mathrm{NS}$ \\
$\quad$ Range & $36-40$ & $36-41$ & \\
Sex-male:female & $12: 9$ & $10: 10$ & $\mathrm{NS}$ \\
Birth weight $(\mathrm{g})$ & $3173(83)$ & $3333(72)$ & $\mathrm{NS}$ \\
Birth length $(\mathrm{cm})$ & $49.0(0.35)$ & $50.4(0.32)$ & 0.008 \\
Head circumference $(\mathrm{cm})$ & $33.8(0.23)$ & $34.4(0.17)$ & 0.08 \\
Birth weight $<10$ th & $6(29)$ & $1(5)$ & 0.045 \\
$\quad$ percentile $(\%)$ & & & \\
Birth length $<10^{\text {th }}$ & $3(14)$ & 0 & 0.08 \\
$\quad$ percentile $(\%)$ & & & \\
Head circumference & $4(19)$ & 0 & $<0.04$ \\
$\quad<10$ th percentile $(\%)$ & & & \\
Discharge day & $3.9(0.3)$ & $2.7(0.3)$ & 0.005 \\
\hline
\end{tabular}


fluoxetine, and six (29\%) citalopram. All infants were delivered spontaneously, and none had a congenital malformation.

No between-group differences were noted in gestational age or maternal background characteristics (Table 1), or maternal gravidy $(p=0.2)$, parity $(p=0.2)$, or smoking habits $(p=$ 0.6 ). None of the women consumed alcohol during pregnancy. Although mean birth weight did not differ between the groups significantly, more neonates in the SSRI group had a birth weight below the 10th percentile for age $(p<0.05)$. The SSRI group was also characterized by a significantly lower mean birth length $(p<0.008)$ and lower mean head circumference $(p=0.08)$, and a greater percentage of neonates with birth length and head circumference below the 10th percentile ( $p=$ $0.08, p<0.04$, respectively). The Finnegan score in the SSRI group ranged from 1 to 11 (median 3). The most frequent symptoms were regurgitations, constant crying, and jitteriness. One infant was transferred to the neonatal intensive care unit because of convulsions. Discharge was delayed in the SSRI group compared with the control group $(p<0.005)$.

Table 2 summarizes the hormone profiles. Compared with controls, the SSRI group was characterized by significantly lower levels of cord blood cortisol $(p<0.03)$ and significantly higher levels of cord blood TSH $(p<0.004)$, and it contained a significantly higher percentage of newborns with TSH levels of more than $15 \mathrm{ng} / \mathrm{mL}$ ( $38 \%$ versus $5 \%, p<0.01$ ). Analysis by sex showed that male infants in the SSRI group had lower levels than male controls of DHEAS $(3527 \pm 539$ versus $6153 \pm 857 \mathrm{nmol} / \mathrm{L}, p<0.02)$ and IGF-I $(78 \pm 20$ versus $129 \pm 19 \mathrm{ng} / \mathrm{mL}, p=0.08)$.

Analysis of variance between the control group and the SSRI-exposed infants subdivided by the specific drug used yielded a statistically significant difference in cord blood IGF-I level ( $\mathrm{F}=4.7, p<0.001)$ (Fig. 1). Post hoc tests revealed a significant difference in cord blood IGF-I between the citalopram and paroxetine subgroups $(36 \pm 10 \mathrm{ng} / \mathrm{mL}$, versus $143 \pm 21 p<0.001)$ and between the citalopram subgroup and the control group $(p<0.003)$. There was also a borderline significant difference between the citalopram and fluoxetine subgroups $(93 \pm 23 \mathrm{ng} / \mathrm{mL}, p=0.07$, 95\% CI -121.4-5.9). No differences were observed between infants exposed to paroxetine or fluoxetine, or between each of these subgroups and the control group.

Although there was no significant difference in mean birth weight, birth length, or head circumference between the citalopram and paroxetine subgroups, the citalopram-exposed neonates were smaller by a mean of $338 \mathrm{~g}$ in birth weight
(95\% CI $-74-749), 1.06 \mathrm{~cm}$ in length (95\% CI $-0.56-2.68)$, and $0.54 \mathrm{~cm}$ in head circumference $(95 \% \mathrm{CI}-0.65-1.73)$. Given these estimate intervals, we could not rule out the possibility of inadequate power to reject the null hypothesis of no difference. It is noteworthy that of the four SSRI-exposed infants born at $36 \mathrm{wk}$, two were in the paroxetine subgroup, and two in the fluoxetine subgroup.

Figure 2 illustrates the effect of SSRI therapy on the expression of placental IGF-IR. The overall expression of IGF-IR was markedly increased in the SSRI group compared with controls $(p<0.01)$, although cord blood IGF-I did not differ between the groups. When evaluated by sex, there was a significant between-group difference for the male neonates $(p<0.04)$ but not for the females $(p=0.09)$.

On univariate analysis in the SSRI group, the Finnegan score was correlated with placental IGF-IR, DHEAS, and cortisol (Fig. 3). Urine 5-HIAA was negatively correlated with DHEA and DHEAS $(r=-0.69, p<0.025)$ and with birth weight $(r=-0.71, p<0.02)$. Birth weight correlated with IGF-I $(r=0.7, p<0.025)$ and DHEAS $(r=0.65, p<0.045)$. None of these correlations was significant in the control group. No significant correlation was found between levels of IGF-I and IGF-IR.

\section{DISCUSSION}

The reports on fetal growth during SSRI exposure are conflicting $(1,2,18,21)$. Some authors noted no difference between SSRI-exposed infants and controls in mean birth weight, birth length, or head circumference, or between SSRIexposed infants with and without transient neonatal symptoms

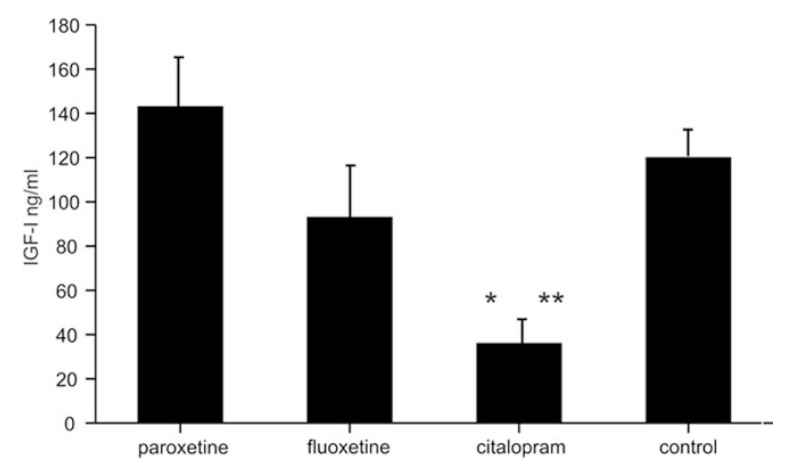

Figure 1. IGF-I cord blood concentration $(\mathrm{ng} / \mathrm{mL})$ by type of SSRI (mean \pm SEM). *citalopram vs. paroxetine $(p<0.001)$ and control $(p<0.003)$. ** citalopram $v s$. fluoxetine $p=0.07$.

Table 2. Hormonal profile of the SSRI-exposed and control groups (mean \pm SEM)

\begin{tabular}{|c|c|c|c|c|c|}
\hline & SSRI & Control & Mean Difference & $95 \% \mathrm{CI}$ & $p$ \\
\hline Prolactin $(\mathrm{ng} / \mathrm{mL})$ & $682(75)$ & $543(50)$ & $139.6(90.7)$ & $-44.1-323.4$ & NS \\
\hline Cortisol $(\mathrm{nmol} / \mathrm{L})$ & $3991(532)$ & $5825(595)$ & $-1834(800)$ & $-3456--212.7$ & $<0.03$ \\
\hline DHEA (nmol/L) & $61.3(3.8)$ & $57.3(4.4)$ & $3.9(5.7)$ & $-7.6-15.6$ & NS \\
\hline DHEAS $(\mathrm{nmol} / \mathrm{L})$ & $4376(576)$ & $4965(537)$ & $-589(789)$ & $-218.6-1008$ & NS \\
\hline $\mathrm{TSH}(\mathrm{ng} / \mathrm{mL})$ & $13.7(1.2)$ & $9.5(0.5)$ & $4.1(1.4)$ & $1.4-6.9$ & $<0.004$ \\
\hline IGF-I (ng/mL) & $96.1(14.6)$ & $119.9(13.4)$ & $-23.8(19.8)$ & $-63.9-16.4$ & NS \\
\hline Urine 5-HIAA (ng/mL) & $12.7(0.7)$ & $14.0(1.0)$ & $-1.3(1.2)$ & $-3.7-1.1$ & NS \\
\hline
\end{tabular}

DHEA, dehydroepiandrosterone; DHEAS, dehydroepiandrosterone sulfate; TSH, thyroid-stimulating hormone; IGF-I, insulin-like growth factor-I; 5-HIAA,5hydroxyindoleacetic acid. 

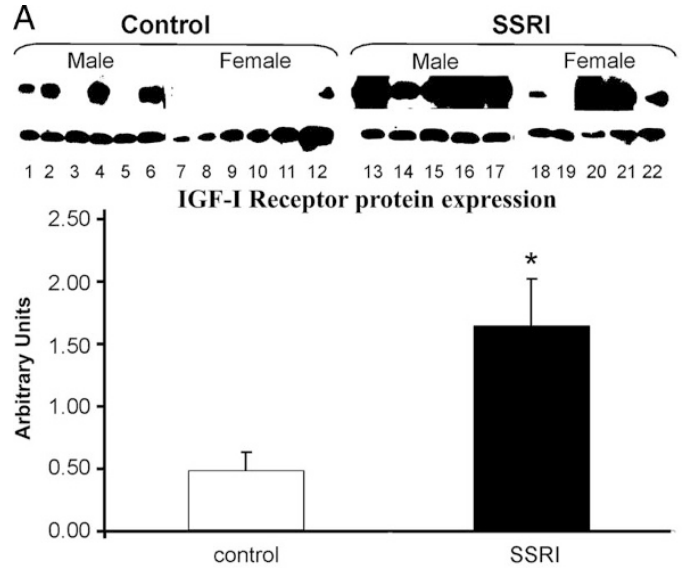
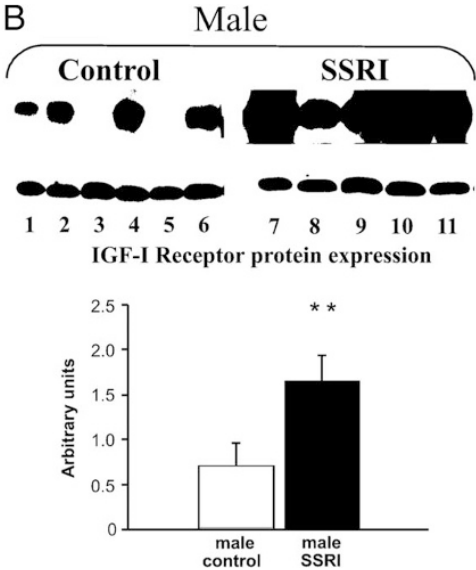

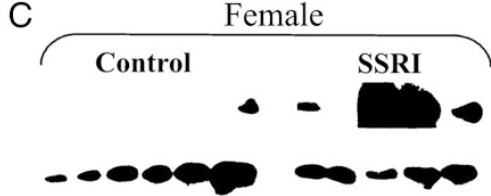

$\begin{array}{llllllllllll}12 & 13 & 14 & 15 & 16 & 17 & 18 & 19 & 20 & 21 & 22\end{array}$ IGF-I Receptor protein expression

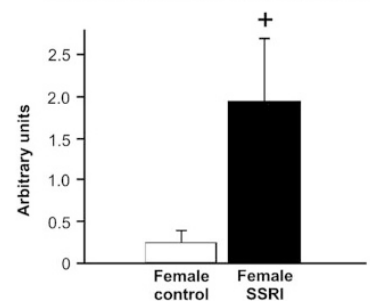

Figure 2. IGF-IR expression in the SSRI and control groups (mean \pm SEM). A. Whole tissue lysates were prepared from placentas of male and female infants born to healthy mothers (lanes 1-12) or mothers treated with SSRIs (lanes 13-22). Western blot analysis was used to identify IGF-1 receptor (upper panel), or antiactin (lower panel). The blot was scanned, and quantification of the relative IGF-1 receptor protein levels is presented graphically. ${ }^{*} p<0.01 B$. Blots shown in $A$ representing the male placentas (left panel) were scanned. Quantification of the relative IGF-1 receptor protein levels is presented graphically. $* * p<0.04$. $C$. Blots shown in $A$ representing the female placentas (right panel) were scanned. Quantification of the relative IGF-1 receptor protein levels is presented. $+p=0.09$.

$(1,2)$. Nevertheless, all three measurements were lower in the SSRI group $(\Delta$ weight $=-97 \mathrm{~g}, \Delta$ length $=-0.3 \mathrm{~cm}, \Delta$ head circumference $=-1.0 \mathrm{~cm})(2)$.

In our study, mean birth length and head circumference of infants exposed to maternal SSRI during pregnancy were lower than control values. In addition, more infants in the SSRI group had a birth weight, birth length, and head circumference below the 10th percentile for age. These differences cannot be attributed to gestational age, which was similar in the two groups.

In support of our findings, a recent population-based study from British Columbia reported that infants of mothers treated with SSRIs had a significantly lower birth weight and gestational age than nonexposed controls. Although maternal depression alone may influence fetal growth and hormonal profile, a comparison of infants of depressed mothers treated with SSRIs and control infants of untreated mothers with matching propensity scores yielded a significantly elevated incidence of birth weight below the 10th percentile for gestational age in the treated group (18).

The reduced birth weight of infants exposed to SSRI in utero has several possible explanations: a) The SSRI group may have had a decreased gestation and/or a higher incidence of premature birth, which may have confounded the analysis of mean birth weight. b) SSRI exposure may have induced an increase in plasma serotonin level, which could lead to a reduction in uterine blood flow and, in turn, reduced delivery of oxygen and nutrients to the fetus (33). However, this explanation disagrees with the lower-than-normal cord blood serotonin levels in SSRI-exposed neonates reported by Laine et al. (1). c) Serotonin and SSRIs may have a direct effect on the growing skeleton and bone homeostasis through their effects on osteoclast differentiation and formation $(34,35)$. This explanation is supported by the observation that growing mice treated with SSRIs had impaired bone mineral accrual because of a reduction in bone formation (36). In a clinical case series of four children treated with SSRIs for various psychiatric disorders for 6 mo-5 y, Weintrob et al. (22) noted a decrease in growth rate, possibly secondary to suppression of GH secretion. This preliminary evidence raises concerns regarding the influence of SSRI intake during pregnancy on the growing fetal skeleton.

In general, the postulated effects of serotonin on anterior pituitary secretion include stimulation of $\mathrm{GH}$ and prolactin and stimulation or inhibition of ACTH, gonadotropins, and TSH (27). Nevertheless, although acute administration of SSRIs increases the secretion of ACTH, corticosterone, and prolactin, their long-term administration causes no consistent alterations (37).

Fetal glucocorticoids are derived from the mother by a maternofetal concentration gradient until the fetal adrenal cortex is activated $(28,29,38)$. Overexposure to maternal glu-
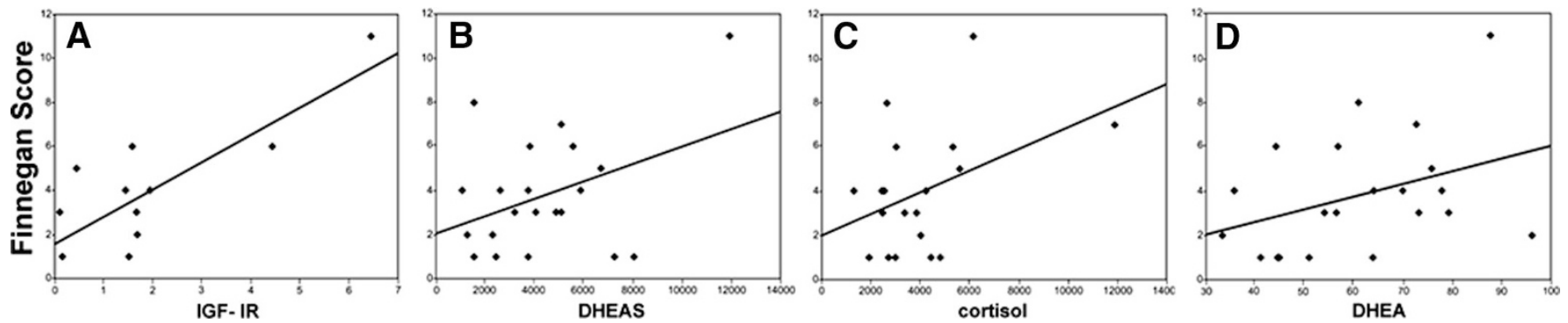

Figure 3. Relationship between the Finnegan score and (A) IGF-IR $(r=0.79, p<0.006),(B)$ DHEAS $(r=0.8, p<0.005),(C)$ cortisol $(r=0.62, p=0.05)$ and $(D)$ DHEA $(r=0.59, p=0.07)$. 
cocorticoids in utero has been shown to retard growth in mammals and human $(38,39)$. Therefore, by modulating IGF-I and IGF binding protein 1 (IGFBP-1) secretion under conditions of fetal stress, cortisol may be regarded as one of the physiologic regulators of fetal growth (40).

There is only limited information about the influence of maternal SSRI treatment on the fetal HPA system. Using a sheep model, Morrison et al. (26) demonstrated a significant increase in fetal plasma ACTH and cortisol levels after 6-8 d of fluoxetine infusion. We found that prolonged fetal exposure to SSRIs was associated with a significant decrease in cord blood cortisol level. Our result of low cortisol in the SSRIsexposed neonates is supported by a recent publication of Oberlander et al. (41) comparing 31 3-mo-old infants with prenatal SSRI exposure with 45 non-SSRI-exposed infants. Prenatal SSRI exposure was associated with altered HPA stress response pattern and reduced basal cortisol levels. These observations suggest an early "programming" effect of prenatal SSRI exposure. Our results of low cortisol are also in line with earlier findings of significantly lower cord blood cortisol levels in small-for-gestational-age than appropriate-forgestational-age infants $(38,40)$.

Possible explanations for the lower cortisol levels are prolonged fetal stress with inadequate maturation of the HPA axis, delayed decline in placental 11 beta-hydroxysteroid dehydrogenase type 2 activity, and a small, insufficient placenta due to intrauterine growth retardation in fetuses with altered hormonal metabolism. Our findings of a positive correlation between the Finnegan score and placental IGF-IR, DHEAS, cortisol, and DHEA (Fig. 3) as well as the inverse association between urine 5-HIAA and DHEA/DHEAS have never been reported. DHEA and its sulfate ester, DHEAS, act as modulators of several neurotransmitter systems including serotonin (42). However, both stimulatory and inhibitory effects have been reported under different experimental conditions. In mice models fed with DHEA supplemented diet, increased or decreased serotonin synthesis and turnover were noted at different doses and in different brain regions (42). The significant inverse correlation between urine 5-HIAA and DHEA/ DHEAS in the present study may suggest increased brain serotonin activity. This, in turn, might be associated with a higher Finnegan score. The specific role of these hormones in SSRI-exposed neonates has yet to be determined.

To the best of our knowledge, our study is the first to measure IGF-I and placental IGF-IR expression in neonates exposed to SSRIs in utero. Although cord blood IGF-I level did not differ between the two groups, separate analysis by gender revealed a lower IGF-I level in the male infants exposed to SSRIs than in the male controls. Within the SSRI group, values were lower in infants exposed to citalopram than in infants exposed to paroxetine $(p<0.001)$ or fluoxetine $(p=0.07)$. The neonates exposed to citalopram were also smaller ( $p=0.08$ for weight). The lack of statistical significance might be attributable to inadequate sample size and type 2 error. We speculate that the elevated level of placental IGF-IR expression in the SSRI group represents a compensatory mechanism for the low IGF-I or cortisol to enhance growth.
Regarding thyroid hormones, SSRIs have been found to significantly decrease triiodothyronine (T3) and thyroxine (T4) levels and to slightly increase TSH levels in subjects treated for major depression (43), but their effect in fetuses has not been investigated. In our study, cord blood TSH level was significantly higher in the SSRI group. None of the SSRIexposed neonates had symptoms of congenital hypothyroidism, and all had normal TSH levels on the national thyroid screening program. Nevertheless, the finding of a cord blood TSH level of $>15 \mathrm{ng} / \mathrm{mL}$ in $38 \%$ in the study group warrants further research on the potential effect of maternal SSRI treatment on neonatal T3 and T4 function.

In our study, the most frequent symptoms in the infants exposed to SSRIs in utero were regurgitations, constant crying, and jitteriness. However, the Finnegan scores were relatively low, and only one infant was transferred to the special care nursery (because of convulsions).

The main limitation of our study, apart from the relatively small number of infants, was our inability to control for the effect of maternal depression itself, rather than the SSRIs, on the anthropometric measurements. Another limitation was our failure to obtain maternal blood at the time of delivery to investigate the possible association between maternal and neonatal hormonal concentrations.

In summary, our study shows that SSRI exposure in utero is associated with impaired fetal growth. This was particularly true in neonates of mothers treated with citalopram. Cortisol, as well as IGF-I and placental IGF-IR expression, may play a role in this effect. Hormones such as glucocorticoids, IGF-I, and thyroxine act as nutritional and maturational signals to adapt fetal growth and development, with possible adverse consequences for later life. Our findings may be added to the list of known side effects of SSRIs and should raise additional concerns about the use of SSRIs during pregnancy. Further follow-up studies are needed to determine their clinical importance.

\section{REFERENCES}

1. Laine K, Heikkinen T, Ekblad U, Kero P 2003 Effects of exposure to selective serotonin reuptake inhibitors during pregnancy on serotonergic symptoms in newborns and cord blood monoamine and prolactin concentrations. Arch Gen Psychiatry 60:720-726

2. Oberlander TF, Misri S, Fitzgerald CE, Kostaras X, Rurak D, Tiggs W 2004 Pharmacologic factors associated with transient neonatal symptoms following prenatal psychotropic medication exposure. J Clin Psychiatry 65:230-237

3. Hampton T 2006 Antidepressants and pregnancy. Weighing risks and benefits - no easy task. JAMA 295:1631-1633

4. Kulin NA, Pastuszak A, Sage SR, Schick-Boschetto B, Spivey G, Feldkamp M, Ormond K, Matusui D, Stein-Schechman AK, Cook L, Brochu J, Rieder M, Koren G 1998 Pregnancy outcome following maternal use of the new selective serotonin reuptake inhibitors. JAMA 279:609-610

5. Sivojelezova A, Shuhaiber S, Sarkissian L, Einarson A, Koren G 2005 Citalopram use in pregnancy: prospective comparative evaluation of pregnancy and fetal outcome. Am J Obstet Gynecol 193:2004-2009

6. Einarson TR, Einarson A 2005 Newer antidepressants in pregnancy and rates of major malformations: a meta-analysis of prospective comparative studies. Pharmacoepidemiol Drug Saf 14:823-827

7. Louik C, Lin AE, Werler MM, Hernández-Díaz S, Mitchell AA 2007 First-trimester use of selective serotonin-reuptake inhibitors and the risk of birth defects. N Engl J Med 356:2675-2683

8. Alwan S, Reefhuis J, Rasmussen SA, Olney RS, Friedman JM; National Birth Defects Prevention Study 2007 Use of selective serotonin-reuptake inhibitors in pregnancy and the risk of birth defects. N Engl J Med 356:2684-2692

9. Bar-Oz B, Einarson T, Einarson A, Boskovic R, O’Brien L, Malm H, Bérard A, Koren G 2007 Paroxetine and congenital malformations: meta-analysis and consideration of potential confounding factors. Clin Ther 29:918-926 
10. Costei AM, Kozer E, Ho T, Ito S, Koren G 2002 Perinatal outcome following third trimester exposure to paroxetine. Arch Pediatr Adolesc Med 156:1129-1132

11. Nordeng H, Lindemann R, Perminov KV, Reikvam A 2001 Neonatal withdrawal syndrome after in utero exposure to selective serotonin reuptake inhibitors. Acta Paediatr 90:288-291

12. Moses-Kolko EL, Bogen D, Perel J, Bregar A, Uhl K, Levin B, Winser KL 2005 Neonatal signs after late in utero exposure to serotonin reuptake inhibitors: literature review and implications for clinical applications. JAMA 293:2372-2383

13. Sanz EJ, De-Las-Cuevas C, Kiuru A, Bate A, Edwards R 2005 Selective serotonin reuptake inhibitors in pregnant women and neonatal withdrawal syndrome: a database analysis. Lancet 365:482-487

14. Ferreira E, Carceller AM, Agogue C, Martin BZ, St-Andre M, Francoeur D, Berard A 2007 Effect of selective serotonin reuptake inhibitors and venlafaxine during pregnancy in term and preterm neonates. Pediatrics 119:52-59

15. Lattimore KA, Don SM, Kaciroti N, Kemper AR, Neal CR, Vazquez DM 2005 Selective serotonin reuptake inhibitor (SSRI) use during pregnancy and effects on the fetus and newborn: a meta-analysis. J Perinatol 25:595-604

16. Chambers CD, Hernandez-Diaz S, Van Marter L, Werler MM, Louik C, Jones KL, Mitchell AA 2006 Selective serotonin-reuptake inhibitors and risk of persistent pulmonary hypertension of the newborn. N Engl J Med 354:579-587

17. Anderson GM, Czarkowski K, Ravski N, Epperson CN 2004 Platelet serotonin in newborns and infants: ontogeny, heritability, and effect of in utero exposure to selective serotonin reuptake inhibitors. Pediatr Res 56:418-422

18. Oberlander TF, Warburton W, Misri S, Aghajanian J, Hertzman C 2006 Neonatal outcomes after prenatal exposure to selective serotonin reuptake inhibitor antidepressants and maternal depression using population-based linked health data. Arch Gen Psychiatry 63:898-906

19. Simon GE, Cunningham ML, Davis RL 2002 Outcomes of prenatal antidepressant exposure. Am J Psychiatry 159:2055-2061

20. Kallen B 2004 Neonate characteristics after maternal use of antidepressants in late pregnancy. Arch Pediatr Adolesc Med 158:312-316

21. Malm H, Klaukka T, Neuvonen PJ 2005 Risks associated with selective serotonin reuptake inhibitors in pregnancy. Obstet Gynecol 106:1289-1296

22. Weintrob N, Cohen D, Klipper-Aurbach Y, Zadik Z, Dickerman Z 2002 Decreased growth during therapy with selective serotonin reuptake inhibitors. Arch Pediatr Adolesc Med 156:696-701

23. Davidson S, Shtaif B, Gil-Ad I, Maayan R, Sulkes J, Weizman A, Merlob P 2001 Insulin, insulin-like growth factors-I and -II and insulin-like growth factor binding protein-3 in newborn serum: association with normal fetal head growth and head circumference. J Pediatr Endocrinol Metab 14:151-158

24. Davidson S, Hod M, Merlob P, Shtaif B 2006 Leptin, insulin, insulin-like growth factors and their binding proteins in cord serum: insight into fetal growth and discordancy. Clin Endocrinol (Oxf) 65:586-592

25. Delarue C, Contesse V, Lenglet S, Sicard F, Perraudin V, Leffebvre H, Kodjo M, Leboulenger F, Yon L, Gallo-Payer N, Vaudry H 2001 Role of neurotransmitters and neuropeptides in the regulation of the adrenal cortex. Rev Endocr Metab Disord 2:253-267

26. Morrison JL, Riggs KW, Chien C, Gruber N, Mcmilen IC, Rurak DW 2004 Chronic maternal fluoxetine infusion in pregnant sheep: effects on the maternal and fetal hypothalamic-pituitary-adrenal axes. Pediatr Res 56:40-46
27. Gilmore DP 1988 Neurosecretion and neurotransmitters of the fetal hypothalamus. In: Polin RA, Fox WW (eds) Fetal and Neonatal Physiology. Philadelphia, PA: WB Saunders Company, pp 2395-2401

28. Fowden AL, Forhead AJ 2004 Endocrine mechanisms of intrauterine programming. Reproduction 127:515-526

29. van Beek JP, Guan H, Julan L, Yang K 2004 Glucocorticoids stimulate the expression of 11beta-hydroxysteroid dehydrogenase type 2 in cultured human placental trophoblast cells. J Clin Endocrinol Metab 89:5614-5621

30. Ward AM, Syddall HE, Wood PJ, Chrousos GP, Phillips DI 2004 Fetal programming of the hypothalamic-pituitary-adrenal (HPA) axis: low birth weight and central HPA regulation. J Clin Endocrinol Metab 89:1227-1233

31. Finnegan LP 1990 Neonatal abstinence syndrome. In: Nelson NM (ed) Current Therapy in Neonatal-Perinatal Medicine-2. Toronto: B.C Decker, pp 314-320

32. Davidson S, Sokolover N, Erlich A, Litwin A, Linder N, Sirota L 2008 New and improved Israeli reference of birth weight, birth length, and head circumference by gestational age: a hospital-based study. Isr Med Assoc J 10:130-134 (IMAJ)

33. Morrison JL, Chien C, Riggs KW, Gruber N, Rurak D 2002 Effect of maternal fluoxetine administration on uterine blood flow, fetal blood gas status, and growth Pediatr Res 51:433-442

34. Bliziotes MM, Eshleman AJ, Zhang XW, Wiren KM 2001 Neurotransmitter action in osteoblasts: expression of a functional system for serotonin receptor activation and reuptake. Bone 29:477-486

35. Warden SJ, Robling AG, Sanders MS, Bliziotes MM, Turner CH 2005 Inhibition of the serotonin (5-hydroxytryptamine) transporter reduces bone accrual during growth Endocrinology 146:685-693

36. Battaglino R, Fu J, Späte U, Ersoy U, Joe M, Sedaghat L, Stashenko P 2004 Serotonin regulates osteoclast differentiation through its transporter. J Bone Miner Res 19:1420-1431

37. Raap DK, Vannde Kar LD 1999 Selective serotonin reuptake inhibitors and neuroendocrine function. Life Sci 65:1217-1235

38. Strinic T, Roje D, Marusic J, Capkun V 2007 Cord blood cortisol level is lower in growth-restricted newborns. J Obstet Gynaecol Res 33:144-150

39. Seckl JR 2001 Glucocorticoid programming of the fetus; adult phenotypes and molecular mechanisms. Mol Cell Endocrinol 185:61-71

40. Cianfarani S, Germani D, Rossi L, Argiro G, Boemi S, Lemon M, Holly JM, Branca F 1998 IGF-I and IGF-binding protein-1 are related to cortisol in human cord blood. Eur J Endocrinol 138:524-529

41. Oberlander TF, Grunau R, Mayes L, Riggs W, Rurak D, Papsdorf M, Misri S, Weinberg J 2008 Hypothalamic-pituitary-adrenal (HPA) axis function in 3-month old infants with prenatal selective serotonin reuptake inhibitor (SSRI) antidepressant exposure. Early Hum Dev 84:689-697

42. Perez-Neri I, Montes S, Ojeda-Lopez C, Ramirez-Bermudez J, Rios C 2008 Modulation of neurotransmitter systems by dehydroepiandrosterone and dehydroepiandrosterone sulfate: mechanisms of action and relevance to psychiatric disorders Prog Neuropsychopharmacol Biol Psychiatry 32:1118-1130

43. Gitlin M, Altshuler LL, Frye MA, Suri R, Huynh EL, Fairbanks I, Bauer M, Korenman S 2004 Peripheral thyroid hormones and response to selective serotonin uptake inhibitors. J Psychiatry Neurosci 29:383-386 